\title{
Methods of estimation of competitiveness of innovation project in foresty sector
}

\author{
Bunkovsky Vladimir Iosifovich \\ Institute of Management, Economics and Law \\ Irkutsk National Research Technical University \\ Irkutsk, Russia \\ bunker59@mail.ru
}

\author{
Ilichev Igor Yurievich \\ Institute of Management, Economics and Law \\ Irkutsk National Research Technical University \\ Irkutsk, Russia \\ Ilichev-@mail.ru
}

\begin{abstract}
According to the authors, the main drawback of the existing methods of assessing the competitiveness of innovative projects is that they involve their comparison with each other. The proposed method involves an individual approach to evaluating the competitiveness of each innovation project, because each innovative project is unique, the same as the set affecting its competitiveness factors. To more objectively assess the competitiveness of individual innovation projects in the forestry sector, it is proposed to use "points of support". The "points of support" of the innovative project are the circumstances that have developed at this point in time (at this stage in the life cycle of the project), due to which the chances for successful development of the analyzed innovation project are increased. Use of this technique to assess the competitiveness of innovative projects implemented in other areas is possible, but only in case of making appropriate adjustments (it is possible to change the "fundamental modules" or the quantitative range of "points of support").
\end{abstract}

Keywords-competitiveness; innovative project; evaluation; forest complex.

\section{INTRODUCTION}

To date, the assessment of the competitiveness of innovation projects is based on the following economic categories:

1. A factor of competitiveness, i.e. the phenomenon or the process affecting the amount of costs.

2. A factor of competitive advantage, meaning that the evaluated project has unique characteristics, which distinguish it from other projects [1].

These categories very logically fit in the essence of any method of assessment of competitiveness. However, in the authors' opinion, their disadvantage is that they imply a comparison.

But the very nature and essence of the innovative project indicates that there no similar innovation projects - each of them unique. In the authors' opinion, it is necessary to carry out an individual assessment of the competitiveness of the innovation project (innovation). To objectively asses the competitiveness of each innovation project, it is necessary to highlight the features and benefits inherent in this particular project "from the inside" and "outside".

In the authors' opinion, to more objectively assess the competitiveness of a particular innovative project, it is necessary to use "points of support".
The "points of support" of the innovative project are the circumstances that have developed at a given point in time, due to which the chances for successful development of the analyzed innovation project are increased.

Features of "points of support" are:

1. "Points of support" can be external (macro-, meso-, micro-level) and internal.

2. "Point of support" of an innovative project is the magnitude of a variable that varies with time, and under the influence of various factors.

3. "Point of support" - the value assigned to the project individually, and not obtained as a result of comparison with other values.

4. For each innovative project, the number and nature of "points of support" are individual [2].

The essence of this proposed technique for assessing the competitiveness of an innovative project in the forestry complex is to determine its "points of support". The more the number of "points of support" of the project, the higher the competitiveness of the project at this point of the life cycle.

The technique for assessing the competitiveness of an innovative project in the forestry complex includes the following algorithm of actions:

1. Identify the factors that affect the competitiveness of the innovation project.

2. Carry out the grouping of factors by sources:

- external environment:

A) macrolevel (macroenvironment);

B) meso level (industry / region);

C) microlevel (microenvironment);

- internal environment.

3. Systematize the factors for the "fundamental modules" that are grouped according to the nature of their origin. For example, economic, technological, infrastructural, etc. (The name of the module corresponds to the origin of the factor).

4. Transform the factors into "points of support". Using any method, analyze factors of competitiveness (real option method, scenario method, factor analysis, integral index of competitiveness, etc.) to single out the most significant analyzed innovative project among them and to assign them the status "Point of support".

5. Identify the type of innovation project. To do this, competitiveness matrix of the project was developed for each "fundamental module", in which for each level of 
competitiveness (the permissible range of "points of support"), the type of project is established.

6. Assess the level of competitiveness of the analyzed innovation project by constructing the resulting matrix, in which each characteristic of the type of innovation project for the "fundamental modules" is estimated by corresponding indicators.

The algorithm of the method is presented in figure 1.

Identification of factors influencing the competitiveness of the analyzed innovation project
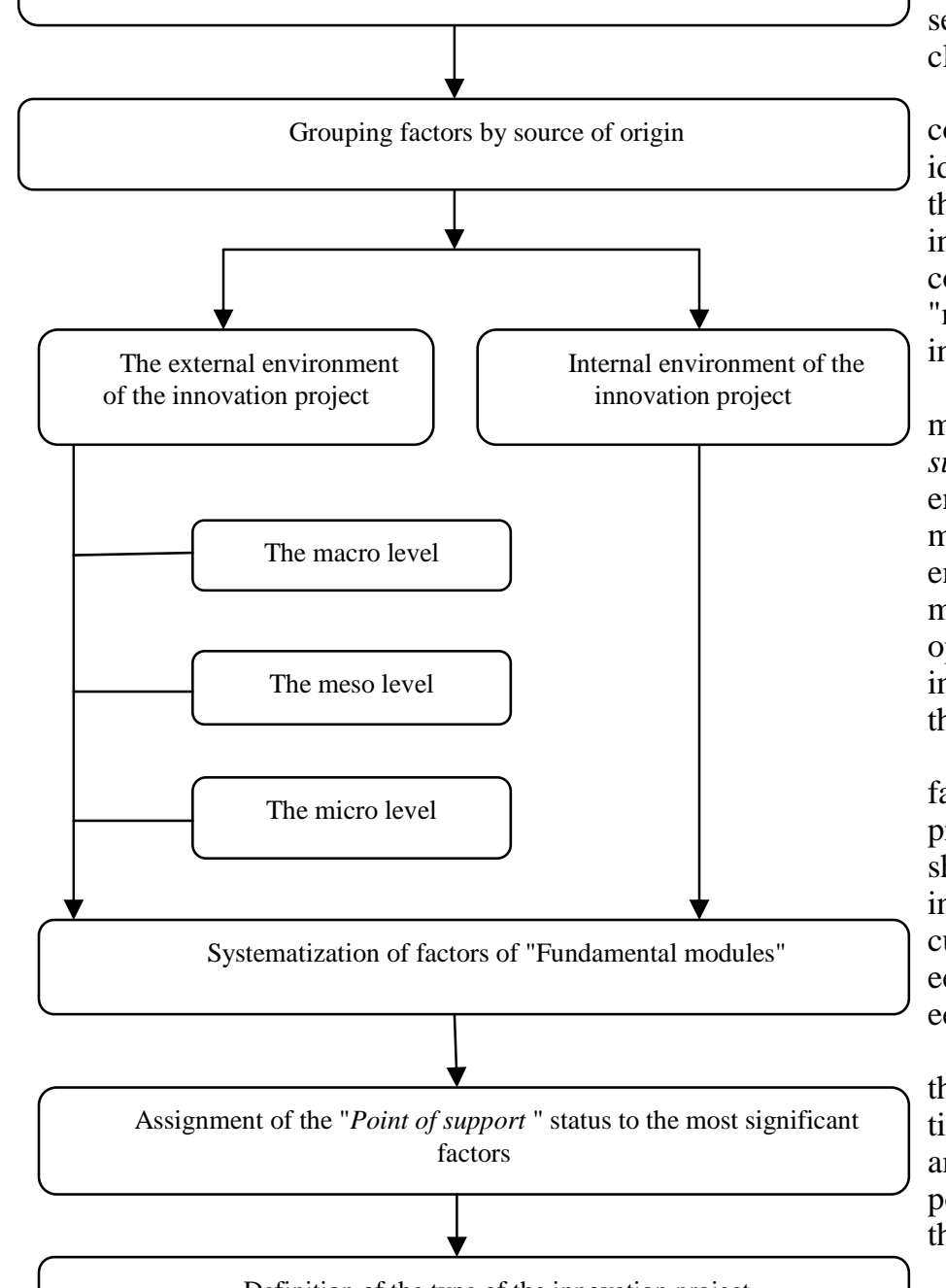

Definition of the type of the innovation project output matrix

Fig. 1. An algorithm for assessing the level of competitiveness of an innovative project in the forestry sector. ${ }^{l}$

\section{RESULTS AND DISCUSSION}

Let us consider the proposed technique in more detail.

${ }^{1}$ Developed by authors
Let us start with the definition of points of support". In tha authors's opinion, the number and quality, the structure and dynamics of points of support" for each innovation project are individual. This is explained simply. First, each innovative project is unique in its kind; and second, the factors, affecting it, change in time and under the influence of various processes that are also not permanent.

In this connection, due to a wide variety of factors and their variability, it is not possible, in the authors' opinion, to develop a clear system for assessing the impact of each factor on the competitiveness of an innovative project in the forestry sector. Nevertheless, factors can be divided into groups, classes, types, types, etc., that is, systematized.

The authors' proposal to systematize the factors of competitiveness of the innovative project will be realized by identifying external and internal "points of support", which in their essence will be competitive advantages, strengths of the innovative project. Their difference from traditional factors of competitive advantages is that the factor itself can be "negative", but it can become "points of support", due to the individual set of characteristics of the innovation project [3].

As is known, the external environment is divided into macro-, meso-, and microenvironment. The "points of support" of the innovative project that are in its external environment can also be from the macro-, meso-, and microenvironment. It is perfectly logical to say that the macro environment for each innovation project is the same, and the microenvironment is individual. However, in the authors' opinion, a specific innovative project may have its own individual "point of support" in the macroenvironment, since the project itself is different from another project.

For example, the economic crisis is the macroeconomic factor [4], and this factor is the same for all innovation projects without exception. It means, for example, inflation, a shortage of cash, defaulted, etc. However, if a specific innovative project involves the launching, for example, of ecurrency [5], or ensures the inflow of foreign capital into the economy, then its external "point of support" will be the economic crisis.

In general, relatively speaking, crises in the economy, in the authors' opinion, are a time of opportunities, including time and possibility of the successful launch of innovations and new ideas. Thus, negative factors, on the contrary, can be positive for the beginning and successful implementation of the project.

External and internal "points of support" of the innovative project are shown in Fig.2.

The nature of the external and internal "points of support" of the innovative project, as can be seen from figure 2, is reduced to the influence of the external and internal environment. External "points of support" can be anywhere, and their number may be different. The figure shows a random set of these points and a random choice of their location. The quality and the number of external and internal "points of support" is determined individually for each innovation project. They can also change over time.

The influence of the macro and microenvironment on the innovation project and its competitiveness may be negative [6], which is shown in figure 2 with a dotted arrow (without "support"), and in this connection will not be "points of 


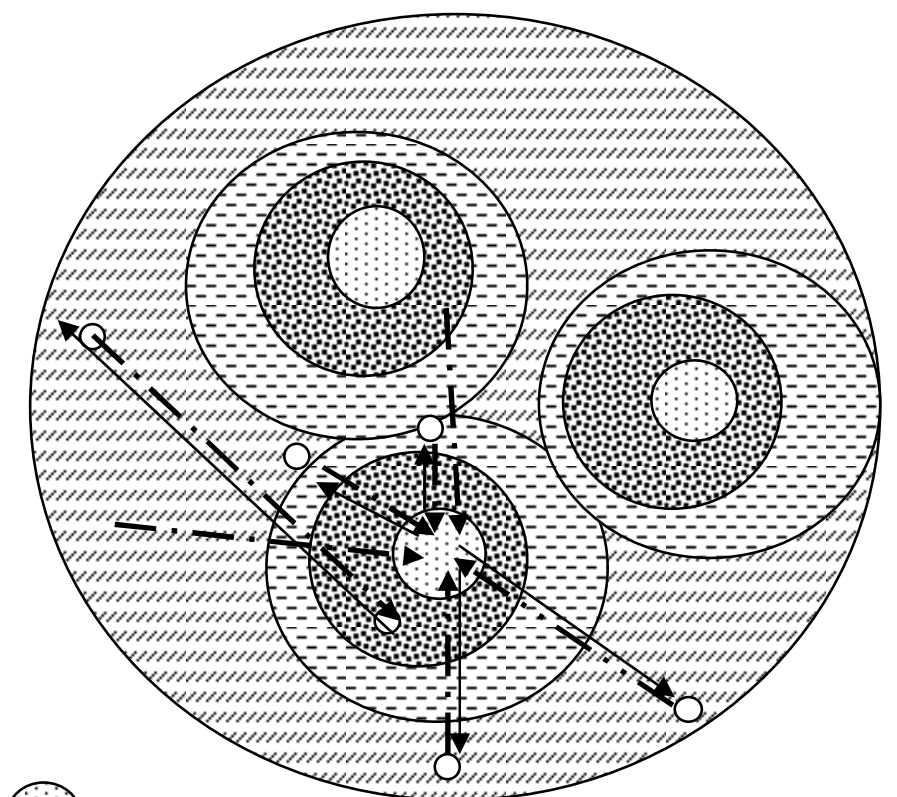

Internal environment of the innovation project

Microenvironment of the innovation project

Branch, where an

innovation project is being implemented

Macro environment of

the innovation project

Support

Influence

Internal points of support

External points of

support

Fig. 2. The nature of the external and internal "points of support" of the innovative project ${ }^{2}$

support". When determining the "point of support", the entire situation is analyzed at a given moment in a separate "fundamental module". That is, the aggregate of all factors is taken into account (both positive and negative), after which, with their account, a "point of support" is defined. 3.

The essence of the proposed technique is shown in figure

It is necessary to note the most important feature: the dotted arrow in figure 3 shows the influence of one or another (positive or negative) factor on the formation of one or another "point of support". This influence can be anything (one factor can influence the formation of one or more "points of suppor ", and vice versa, several different factors can influence the same "point of support", forming it). This is due to the uniqueness of the analyzed innovation project.

Figure 3 shows a random selection of the above-described links. These links can be of a different nature: they can be economic, political, etc., so they are formed into "fundamental modules", and are grouped by the nature of origin (macroenvironment, industrial environment, microenvironment, internal environment).

Let us create the "fundamental modules" and start with the macroenvironment, which is "a combination, symbiosis of various factors - economic, technological, social, institutional and others, which at the level of the economy as a whole support processes of acquisition, production, diffusion and adaptation of new technological knowledge "[6].

Accordingly, the "fundamental modules" in this group of factors will be as follows:

1. "Economic module".

2. "Technology module".

3. "The social module".

4. "Institutional module".

5. "Political Module".

6. "The module of technogenic / environmental factors".

The sectoral group of factors (meso level), influencing the competitiveness of the innovation project, contains the following "fundamental modules":

1. "Infrastructure module".

2. Module "Industrial potential of the industry".

3. Module "State of the industrial markets."

4. Module "Readiness of the industry for innovations" / "Innovative activity of the industry".

5. Module "Scientific and technical reserve of the industry".

6. "Personnel module".

7. Module "The state of related industries".

8. "Module of investment activity in the industry".

9. Module "Direction of the industry" (direction of the industry development) ".

10. Module: "State regulation (support) of the industry".

1. Module "Industry specificity".

Next, let us present the main "fundamental modules" of the microenvironment, which directly affects the competitiveness of the innovation project:

1. "Infrastructure module".

2. Module "Innovative Project Infrastructure".

3. Module "Sources of financing of an innovative project".

4. Module "Market counterparties of the innovative project".

5. Module "Geographical position".

Let us consider the "fundamental modules" of the internal environment of the innovative project that will assess the quality of the internal content, the filling of the innovative project:

1. "Organizational module".

2. "Management module".

3. "Personnel module".

4. "Production and technical module."

5. "Scientific and technical module".

6. "Marketing module".

7. "Information module".

8. "Financial and economic module."

9. Module "Effects and efficiency of the innovation project".

\footnotetext{
${ }^{2}$ Compiled by the authors
} 


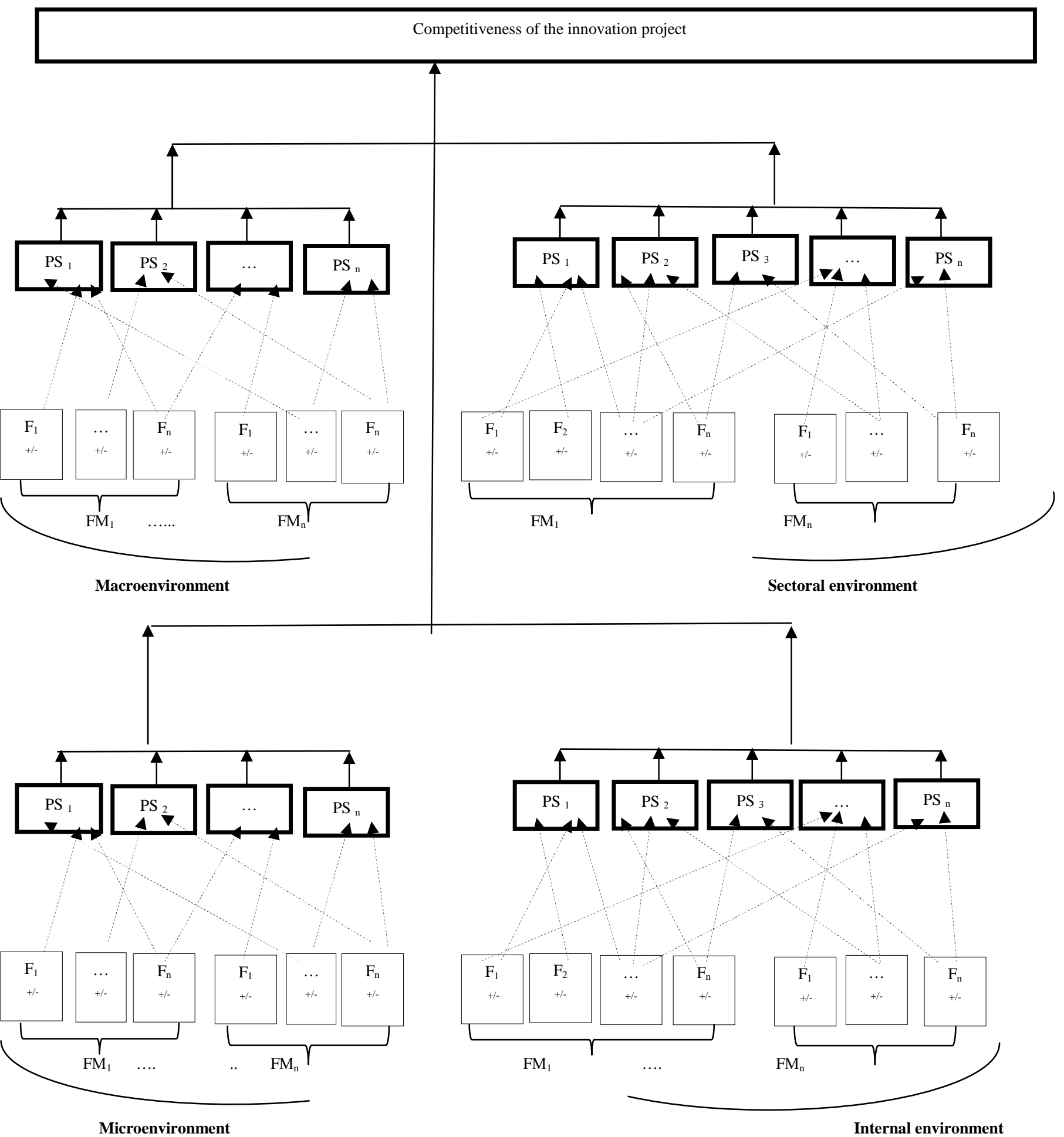

Fig. 3. The essence of the proposed methodology for assessing the competitiveness of an innovative project for "points of support." $\sum^{3}$

Legends to the picture:

PS - "Point of support";

$\mathrm{F}$ - factor (+/-) that can be positive or negative;

FM is a "fundamental module".

${ }^{3}$ Developed by authors 
For each "fundamental module", the number of "points of support " of the innovation project is determined. The more "points of support" the analyzed innovative project has, the higher its competitiveness.

The competitiveness of an innovative project is determined by the following formula:

$\mathbf{K}=\sum_{\mathrm{t}=\mathrm{h}}\left(\mathbf{a}_{1}+\mathbf{a}_{2}+\cdots+\mathbf{a}_{\mathrm{n}}\right)+\left(\mathbf{b}_{1}+\mathbf{b}_{2}+\cdots+\mathbf{b}_{\mathrm{n}}\right)+\left(\mathbf{c}_{1}+\mathbf{c}_{2}+\cdots+\mathbf{c}_{\mathrm{n}}\right) \rightarrow \max (1)$

where $\mathbf{K}$ - competitiveness of the analyzed innovation project, $\mathbf{h}$ - stage of the life cycle of the analyzed innovation project, a - the "points of support " of the external (macro-, meso-) environment from the corresponding "fundamental module", b - "points of support " of the microenvironment from the corresponding "fundamental module", c - internal "points of support" from the corresponding "fundamental module", n - the number of "fundamental modules".

Further, the authors summarize all the "support points" of the innovative project for each "fundamental module".

Then it is necessary to determine the type of the innovation project and the level of its competitiveness for each "fundamental module". To do this, for each "fundamental module", the competitiveness matrix of the project was developed, in which for each level of competitiveness (the permissible range of " "points of support" ), the type of project is established.

Depending on the type of innovation project being analyzed, the range of values of "points of support " from the macroenvironment will be different. For example, monoprojects and megaprojects essentially differ in scale among themselves [7]. Accordingly, for the mono project, the range of "points of support" of the external (macroenvironment) will be smaller than that for the megaproject, since the second assumes a global character of the international / national economy, where it will be important to take into account all processes (from currency exchange rates - to international legislation). For a monoproject, it will be much more important to find more internal or sectorial "points of support". According to this logic, the proposed methodology for assessing competitiveness is being built.

The branch "points of support" is the most important for more "serious" innovation projects (industry, mega and multiprojects) [8]. For smaller innovative projects, in the authors' opinion, the most important are the "points of support" from the microenvironment. For example, basic innovations are characterized by the conditions of implementation in alliances, clusters, associations (that is, they need external influence), but innovations of improvement, on the contrary, need a powerful internal potential. Proceeding from this, innovative projects, involving the implementation of basic innovations [9], should have more external (sectoral) "points of support"; and innovative projects that implement innovation improvements - on the contrary, internal "points of support". This logic formed the basis for determining the appropriate range of values of external and internal "points of support".

Based on the ranges of values of "points of support", established in matrices of competitiveness, it is evident that, for example, an innovative project such as "the development of a new market", for a high level of competitiveness, should have more than 31 external "points of support" of the macroenvironment, not less than 46 industry "points of support", as well as at least 33 "points of support" of the microenvironment and more than 35 internal "points of support".

For comparison, an innovative project of the "new product" type will be characterized by a high level of competitiveness with a somewhat different quantitative set of "points of support":

- from 32 and more points from the macroenvironment;

- from 46 sectorial "points of support";

- from 26 "points of support" of the microenvironment;

- from 31 and more internal "points of support".

This is due to the fact that for an innovative project like "the development of a new market", macro environment is more important than the industry, since the market assumes both an interbranch level and related industries. And for the "new product" type project, on the contrary, the most important is the favorable situation in the industry. For example, the market of wooden housing construction in Russia is now very actively developing (the market is new, young, based on innovative technologies)[10], which is most likely due to the macro environment, and not to the forestry sector (in particular, population income growth, availability of mortgage lending, state programs "Housing " etc.). The development of this market in turn affected the development of the forestry sector (in particular, the sawnwood segment).

Further, let us make the final matrix of an estimation of the level of competitiveness of the analyzed innovative project. In this matrix, each characteristic of the type of innovative project for "fundamental modules" is estimated by the following indicators:

$$
\begin{aligned}
& \text { - "absent"; } \\
& \text { - "low"; } \\
& \text { - "average"; } \\
& \text { - "tall". }
\end{aligned}
$$

\section{CONCLUSION}

Thus, the developed methodology implies an individual, approach to assessing the competitiveness of each analyzed innovation project, since each innovation project is unique, and a set of factors, affecting its competitiveness, is unique.

It should be noted that this technique involves the use of well-known methods of evaluation without any restrictions.

Another feature of the proposed technique is the use, along with traditional methods of assessing competitiveness, of the expert method, which gives the most qualitative result, since traditional methods can not take into account a set of all factors that are wagging on the competitiveness of the project.

The technique is designed to assess the competitiveness of innovation projects in the forestry sector. However, its application for the evaluation of innovative projects implemented in other sectors is possible, but with appropriate adjustments (it is possible to change the "fundamental modules" or the quantitative range of "point of support". 


\section{References}

[1] A.G. Granberg, «Simulation of the spatial development of the economy», Strategic planning in regions and cities of Russia, St. Petersburg, № 9, pp. 32-34, 2014.

[2] V.G. Medynsky, Innovative management, Moscow: INFRA-M, 2002

[3] T.L. Bezrukova, «Evaluation of the clusterization potential of the forest sector and its determining factors» [Electronic resource], Socioeconomic phenomena and processesvol. № 12, pp. 25-30, 2015. Access mode: http://cyberleninka.ru/article/n/otsenka-potentsiala-klasterizatsiilesnogo-sektora-i-opredelyayuschih-ego-faktorov

[4] J.A. Schumpeter, The theory of economic development, Moscow: Progress, 1982
[5] V.P. Oreshin, E.A. Kuvshinova, «Structural transformations in the economy: transition to an innovative way of development», Bulletin of Moscow University. Ser. 6, The Economy, № 3, pp. 107-113, 2014.

[6] R. Baytasov, Innovative management: tutorial [Electronic resource], Access mode: http://www.researchgate.net/publication/263234894

[7] A.N. Barykin, Designing innovations [Electronic resource], Access mode: http://www.lagoda.by/docs/10319.pdf

[8] S.A. Golubev, D.V. Yugai, Functional modeling using the IDEF0 methodology: tutorial, St. Petersburg, 2014.

[9] A.A. Trifilova, Evaluation of the effectiveness of innovative development of the enterprise, Moscow: Finance and Statistics, 2005.

[10] K.S. Sablin, «The role of the institutional environment in the formation of development institutions», Journal of Institutional Studies, Volume 4, №2, 2012. [Electronic resource], Access mode: http://ecsocman.hse.ru/data/2012/08/10/1265219943/jis4.2-3.pdfG. 